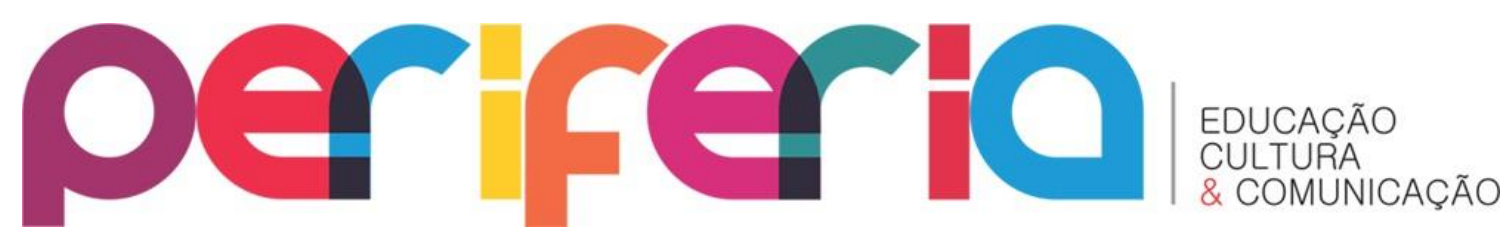

\title{
ESCOLAS MULTISSERIADAS NO CONTEXTO DA AMAZÔNIA
}

\author{
José Valderi Farias de Souza ${ }^{1}$ \\ Rafael Marques Gonçalves ${ }^{2}$
}

$\mathrm{O}$ artigo discute o conceito de trabalho em escolas multisseriadas e os processos de intensificação do trabalho na educação do campo/floresta. O texto aponta que ser professor do ensino fundamental em escolas rurais implica lecionar diversas áreas de conhecimento para diversas séries, assegurando o domínio de todos os alunos nas diferentes áreas curriculares. Por conseguinte, na Amazônia, a singularidade de seus espaços e os desafios que requerem ser superados, exigem dos educadores, nem sempre especialistas, o enfrentamento de uma realidade para as quais, talvez, não foram devidamente preparados. As inquietudes dos homens e mulheres da floresta se projetam em outros contextos, que não aqueles impostos pelo currículo transplantado da cidade aos espaços rurais. O professor do campo neste contexto é, em sua gênese, polivalente, intensificado e precarizado. A pesquisa, em seu estágio inicial, aponta os elementos que tornam o trabalho docente no campo imensamente intensificado, na busca de redimensioná-lo e contribuir para uma crítica profunda das condições de trabalho do professor neste espaço.

Palavras-chave: Intensificação; Profissão docente; Ensino Multisseriado; Currículo.

\section{MULTISSERIE SCHOOLS IN THE AMAZON CONTEXT}

\begin{abstract}
To discuss the concept of work singular teacher and the processes of intensification of work in the field education/rainforest. teacher in the field. The text indicates that being a teacher of elementary education in rural schools involves teaching various areas of knowledge, ensuring the domination of all students in the different areas of the curriculum for various series. Therefore, in the Amazon, the singularity of its spaces and the challenges that need to be overcome, require of educators, not always experts, the facing of a reality for which, perhaps, were not properly prepared. The anxieties of the men and women of the rainforest
\end{abstract}

\footnotetext{
${ }^{1}$ Mestre em Educação. Professor da Universidade Federal do Acre. Membro do grupo de pesquisa Núcleo Interdisciplinar de Estudos e Pesquisa em Trabalho, Educação e Políticas Educacionais. Email: valderi-souza@hotmail.com

${ }^{2}$ Professor da Universidade Federal do Acre (Centro de Educação e Letras - Campus Floresta de Cruzeiro do Sul). Doutorando em Educação pela UERJ/ProPEd. Membro do GT 12-Currículo da ANPEd e da Associação Brasileira de Currículo - ABdC. Líder do Grupo de Pesquisas em Memórias, Identidades, Currículos e Culturas - GpMICC/CEL/UFAC. E-mail: rafamg02@gmail.com
} 


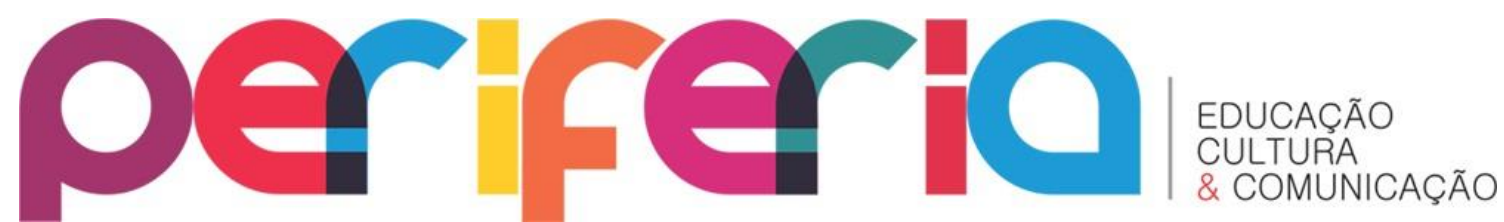

project in other contexts, than those imposed by the curriculum transplanted from the city to the rural areas. The teacher of the field in this context it is, their genesis, multivalent, intensified and precarious. The studies, in its initial stage, indicates the elements that make the teaching work in the field immensely intensified, in search of resizing it and contribute to a deep criticism of the working conditions of teachers in this space.

Keywords: Intensification. Working conditions of teachers. Multisserie.

\section{Introdução}

Neste texto, busca-se problematizar uma questão dada como natural: ser professor dos anos iniciais do ensino fundamental em escolas rurais ou urbanas implica lecionar diversas áreas de conhecimento, assegurando o domínio de todos os alunos nas diferentes áreas curriculares. Contudo, nosso entendimento, é que, além dessa polivalência disciplinar, que por si só já merece atenção, trabalhar em contexto de monodocência no campo é se colocar diante de vários outros conhecimentos que precisam ser mobilizados pelos professores nesses contextos para dar conta da tarefa de ensinar para varias séries em única sala de aula.

Nossa atenção, a priori, volta-se para o contexto rural, onde temos visto este fenômeno perpassando áreas e dimensões que ultrapassam o trabalho docente como simples ato de ensinar. $\mathrm{O}$ trabalho docente em escolas monodocentes define-se como ação educativa consciente que se constitui no ensino, na gestão de contextos educativos, na gestão das aprendizagens de todas as áreas do conhecimento que perpassam o currículo escolar, na gestão comunitária, na organização do espaço escolar e na representação imagética da escola enquanto instituição estatal.

O professor que atua nesses contextos é instigado constantemente a se reinventar, criar formas e instrumentos pedagógicos capazes de atender a diversidade das demandas e desafios encontrados no campo/floresta. Porém, na Amazônia, a singularidade de seus espaços e os desafios que requerem ser superados, exigem dos educadores, nem sempre especialistas, o enfrentamento de uma realidade para as quais, talvez, não foram devidamente preparados. As inquietudes dos homens e mulheres da 


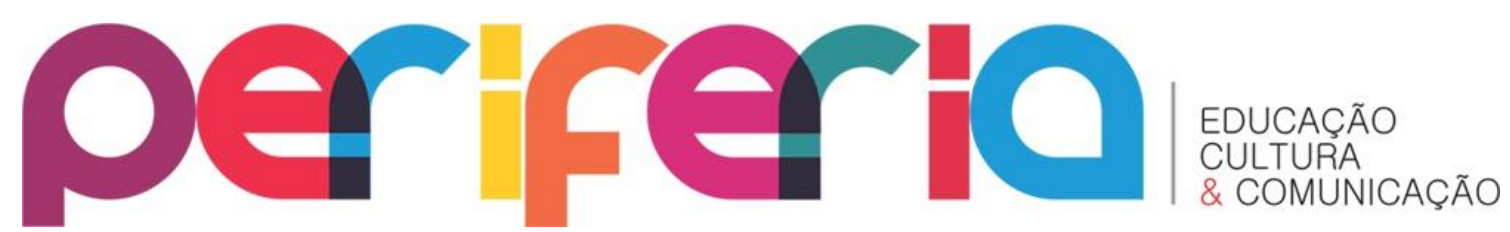

floresta se projetam em outros contextos, que não aqueles impostos pelo currículo transplantado da cidade aos espaços rurais.

Conciliar o diálogo entre os saberes tradicionais dos povos autóctones às reflexões ensejadas no pensamento moderno e reflexivo dos movimentos sociais organizados talvez seja o caminho para a construção de uma escola mais próxima dos sujeitos.

Nesse sentido, o artigo vem dialogar, num primeiro momento, com algumas concepções acerca dos termos monodocência/unidoceência, para em seguida tentar compreender as interfaces e teceduras que permeiam e desafiam as realidades das práticas pedagógicas do docente em salas multisseriadas, na região do Alto Juruá/AC. No decorrer do trabalho algumas questões dialógicas são apresentadas na tentativa de procurar entender como se dá a polivalência do trabalho docente nos espaços de aprendizagens, por um professor, muitas vezes leigo.

\section{Sobre os caminhos que seguimos...}

Este trabalho é resultado da pesquisa em desenvolvimento sobre a intensificação do trabalho docente na educação do campo, região do Alto Juruá/AC. Partimos da compreensão que os dados qualitativos são importantes para subsidiar nossa pesquisa e que eles são o ponto de partida para a compreensão do "real", integrando e relacionando elementos teóricos e práticos. Assim, a pesquisa assume os pressupostos do Materialismo Histórico como forma de compreensão do objeto e da realidade. Acreditase que:

Não há uma relação de exterioridade na pesquisa do social, na pesquisa do sócio-histórico, na pesquisa do cultural, há uma relação de autoimplicação, que não é uma relação de identidade, mas uma relação de unidade [...]. É que Marx parte da noção de que não há nada irredutível na realidade social. Para Marx a realidade social é um complexo constituído de complexos. [...]. Trocando em miúdos, há em Marx sempre o enorme cuidado com a especificidade das distintas instâncias sociais. Isso põe a centralidade da categoria teórica da mediação. Essa categoria é uma categoria central em Marx. [...]. Na verdade, a questão posta por Marx é a questão da análise da particularidade, que ele entende como um campo de mediações entre a universalidade e a singularidade (NETTO, 1997, p. 81-82). 


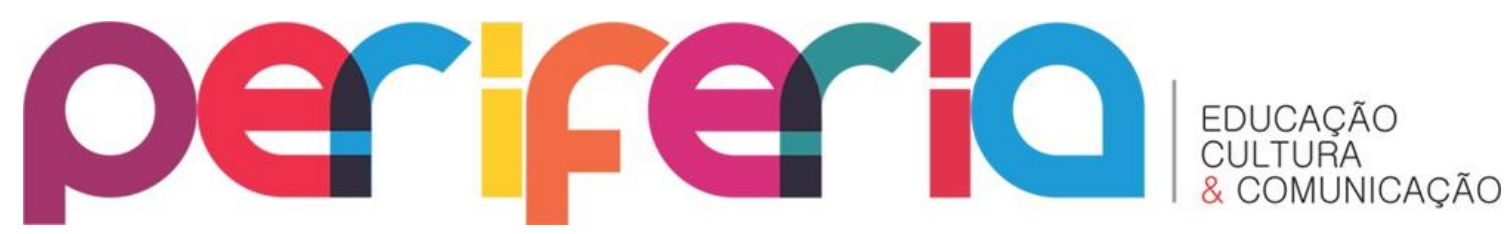

Portanto, a pesquisa é a interpretação da realidade pelo movimento do pensamento, captando as contradições existentes e suas múltiplas relações. A compreensão das contradições do processo deve sempre levar em consideração o contexto histórico e as condições materiais em que este processo ocorre. Por isso as categorias contradição, qualidade, mediação e totalidade estão presentes no processo de apreensão da realidade estudada.

Como procedimento metodológico adotamos os seguintes passos:

1) Pesquisa bibliográfica que visou entender teoricamente os processos de intensificação e a educação do campo a luz da compressão marxiana da história.

2) No segundo momento, foram realizadas visitas e entrevistas com professores que atuam na escola do campo, e também em projetos governamentais de educação do campo no Acre, a saber o programa Asas da Florestania.

3) A partir destes dados empíricos coletados em campo, começamos a traçar um conjunto de condições evidenciadas nos questionários de entrevistas que caracterizam a atuação intensificada destes professores.

4) Em seguida, a luz da teoria marxista e dos dados do campo estabelecemos as duas categorias inicias de análise: Trabalho monodocente e Intensificação, que passaram a ser analisados no contexto do Programa Asas da Florestania.

Neste artigo, lançamos mão da pesquisa bibliográfica empreendida para entender a intensificação do trabalho docente em escolas monodocentes e, apresenta alguns dados da pesquisa empírica. Os instrumentos utilizados nesta primeira análise foram: a entrevista - com a intenção de obter dados objetivos e subjetivos na fala dos sujeitos envolvidos na pesquisa e a observação direta e estruturada para a coleta e registro de dados que não forem verificáveis na entrevista.

\section{Escolas monodocente}

Etimologicamente monodocência refere-se ao regime de trabalho em que um professor assegura todos os domínios das diferentes áreas curriculares. Formada a partir 


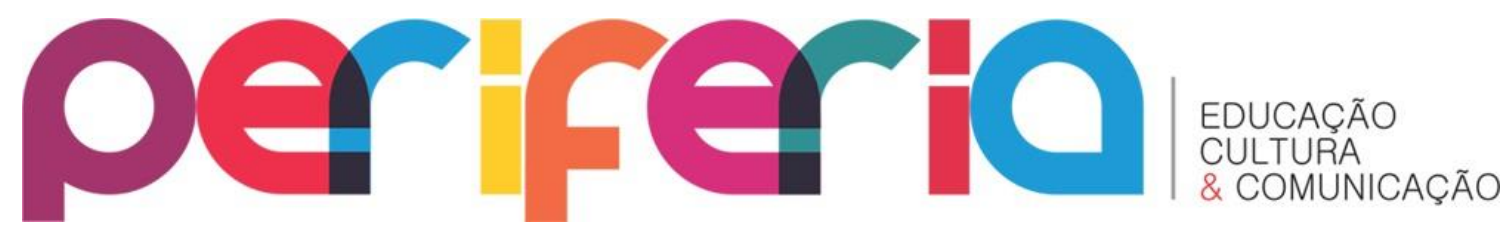

do prefixo grego mono (um) e da palavra latina docência (do latim docere), o termo procurar nominar um fenômeno muito conhecido desde a invenção da escola como instituição social, que é a atuação de um único professor no ensino fundamental de $1^{\circ}$ ao $5^{\circ}$ ano ou em salas multisseriadas, no caso da educação rural.

Para Oliveira (2012):

\begin{abstract}
A monodocência tem uma grande tradição histórica relacionada, por um lado, com as condições com que foi iniciado o Ensino Primário, ministrado em escolas com poucos alunos, separadas entre si e em que era irrealista colocar professores por áreas disciplinares, e por outro lado, com necessidades curriculares e pedagógicas (p. 5).
\end{abstract}

Porém, como é notório "a monodocência foi, e é, susceptível de críticas, na medida em que o professor, funcionando com a sua turma, no isolamento da sua sala de aula, pode não criar redes de intervenção" (OLIVEIRA, 2012, p.2), e com seu isomorfismo pedagógico pode perpetuar práticas que não sejam transformadoras e/ou produtoras de ensino de qualidade socialmente referenciado.

Por outro lado, este mesmo professor precisa ter sua prática redimensionada, pois ele não é simplesmente o aplicador de um conhecimento estanque, parcelar ou disciplinar. É, um mobilizador de outros "saberes" que lhe são exigidos em contextos de monodocência, pois esta implica:

Que a relação pedagógica professor / aluno esteja muito dependente da relação pessoal que se estabelece. Há uma grande aproximação afectiva entre o professor e os alunos, que lhe permite conhecer as particularidades de cada um, pelo que o professor não se deve assumir como mero instrutor, quando tem grandes responsabilidades pelos aspectos de desenvolvimento global da criança não só a nível afectivo mas também ao nível emocional, social e moral (OLIVEIRA, 2012, p. 5).

Para Formosinho (1998, pp. 30 - 31), a

Monodocência exige a polivalência curricular do professor. Para ser pedagogicamente eficaz, esta monodocência exige continuidade (...) exige que o mesmo grupo de alunos progrida com o mesmo professor, ao longo da escolaridade das aprendizagens básicas (...). As mudanças a promover são as de transformar a monodocência integral em monodocência com apoio especializado (...) transformar a monodocência individual em pluridocência de valências diversificadas no seio de uma equipa educativa (p. 30-31). 


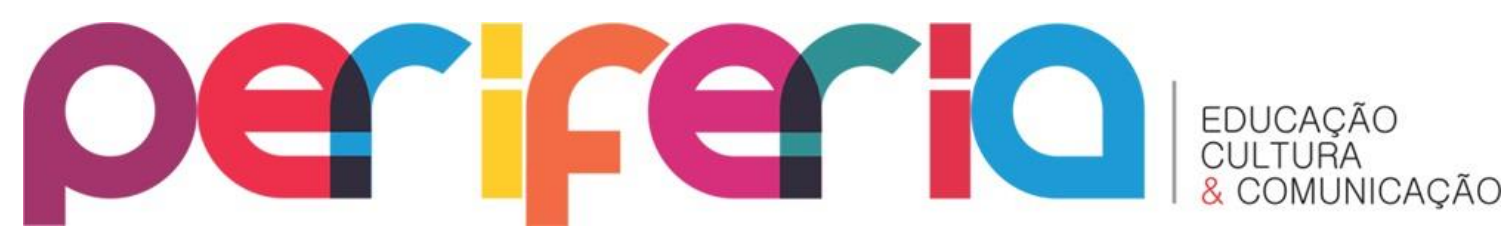

O interessante é que em termos de legislação educacional no Brasil, pouco evoluímos na superação desta problemática, ainda temos a mesma estrutura profissional dos mestres escolas ou mestres das primeiras letras, trabalhando em escolas do campo. De certa forma isso reflete os interesses daqueles que financiam a educação ou que criam as políticas educacionais.

Sem excluir o trabalho monodocente realizado em contexto urbano, é no contexto de educação do campo que se pode observar o fenômeno das escolas monodocentes perpassando o trabalho docente em todas as suas dimensões criando mecanismos de intensificação, diversificação, polivalência, versatilidade, flexibilidade, exigindo deste trabalhador policompetências para executar o seu trabalho com diversas séries em uma mesma sala de aula.

Pensar essa nova escola a partir dos sujeitos do campo enseja na construção de novos parâmetros reflexivos, que insira nas discussões e debates àqueles sujeitos historicamente esquecidos. É fundamental ouvir as várias vozes desse povo diverso, de cultura tão multifacetada quanto a diversidade de suas práticas, rituais e natureza. A escola do campo, efetivamente, só será do campo quando considerar as experiências, práticas e visões de mundo dos sujeitos que lá residem, como nos alerta Molina (2006):

\begin{abstract}
A desvalorização dos conhecimentos práticos/teóricos que trazem os sujeitos do campo, construídos a partir de experiências, relações sociais, de tradições históricas e principalmente, de visões de mundo, tem sido ação recorrente das escolas e das várias instituições que atuam nestes territórios. Como romper com o silenciamento destes saberes e legitimar outros processos de produção do conhecimento, trazendo-os para dentro da escola do campo, para dentro das universidades? (p. 12).
\end{abstract}

A Lei de Diretrizes de Bases da Educação Nacional - Lei 9394/96 - no artigo 28, incisos I, II e III, destaca a necessidade de construção, pelos sistemas de ensino, da escola básica do campo adequadas às peculiaridades dos sujeitos que lá residem, conteúdos curriculares e metodologias apropriadas às áreas necessárias e interesses dos alunos da zona rural, organização escolar própria e adequação à natureza do trabalho na zona rural (BRASIL, 1996). 


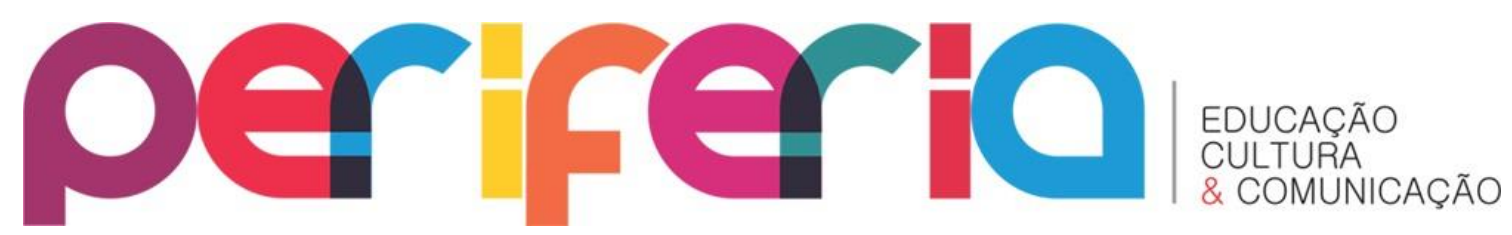

O que se percebe é que a escola do campo, mesmo constando como prioridade na lei, na prática o que se tem é uma escola alijada de seus fundamentos teóricos/práticos, onde educador e sujeitos do campo, esquecidos pelo Estado, se veem na condição de improvisar um currículo híbrido, falseado por concepções distorcidas sobre o campo.

\section{As Faces dos programas e projetos de educação do Campo e rural no Acre}

No estado do Acre, nas últimas duas décadas tem sido feito um esforço institucional considerável na tentativa de ofertar educação a nível básico aos sujeitos do campo/floresta nas mais longínquas comunidades. Esse processo tem início por volta de 1999 com a ascensão ao poder de um novo grupo político, historicamente ligado aos movimentos sociais.

À época os índices de analfabetismo, retenção e fracasso escolar, segundo Almeida Júnior (2006), baseado em dados do INEP, oferece um retrato real das precárias condições em que se encontrava a educação no estado.

\footnotetext{
Os altos índices de reprovação, evasão contrastam com investimentos insignificantes como programas de correção de fluxo, como aceleração de aprendizagem. Em 1998, a defasagem idade-série no ensino fundamental era 59\% e no ensino médio o índice chegava a 71\% (ALMEIDA JUNIOR, 2006, p. 20).
}

Segundo o discurso oficial (ACRE, 2012) na tentativa de superar essas adversidades e o esquecimento que os sujeitos do campo historicamente foram legados, estabeleceu-se uma coordenação de educação rural, a partir da qual começaram a ser pensadas e elaboradas as políticas públicas visando atender as distintas realidades da floresta, para isso investiu-se em formação de educares e na construção reflexiva de uma proposta pedagógica/curricular pautada nas vivências, culturas e olhares do homem e da mulher do campo.

Pensar, porém, a educação do campo/floresta a partir do Estado, é no mínimo um equívoco grave, na medida em que se entende que as políticas públicas historicamente construídas para esses espaços foram/são equivocadas. A Educação do Campo não pode ser confundida com Educação Rural, as duas carregam profundos 


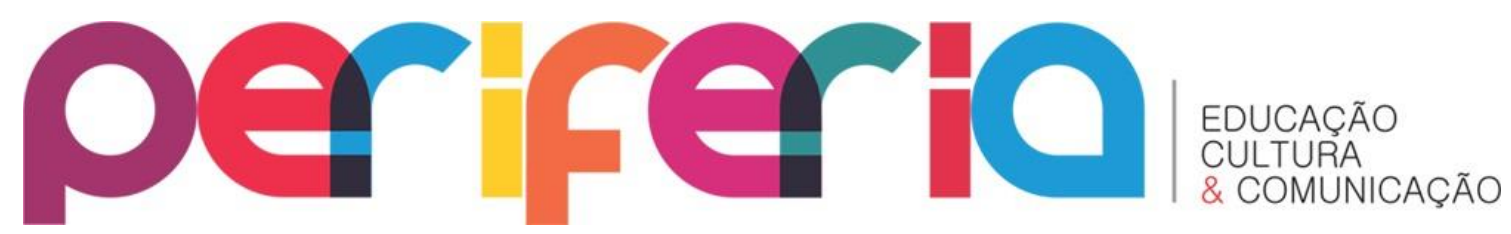

antagonismos e contradições. Sobre esse sentido é singular o que nos diz Arroyo (2006, p. 16): "A educação do Campo nasceu dos pensamentos, desejos e interesses dos sujeitos do campo [...]. A Educação Rural nasceu da cabeça dos ruralistas como forma de subordinação dos camponeses [...]".

Em 2005, fincado nas bases contraditórias das políticas estatais e equidistante das realidades e das vontades dos sujeitos do campo foi implantado, em parceria com a Fundação Roberto Marinho, o Programa Asas da Florestania, que num primeiro momento visava atender apenas o público do Ensino Fundamental, sendo mais tarde o atendimento ampliado para o Ensino Médio e posteriormente à Educação Infantil (Asinhas). Seus recursos são oriundos do Governo do Estado do Acre e dos financiamentos com o Banco Mundial.

Diante dos esclarecimentos trazidos por Miguel Arroyo é possível questionar, se, e em que medida é possível a edificação da escola do campo ancorada no pensamento do Banco Mundial e da Rede Globo? Essas instituições tendem a olhar o campo como lugar de atraso e ignorância, onde seus sujeitos podem ser dispostos como mão-de-obra fácil, de salários pauperizados por um Estado ausente.

É urgente que se saiba que na Amazônia a vida é mais pungente, mais presente e diversa, mas só é capaz de enxergá-la aqueles despossuídos de preconceitos e verdades dogmáticas capitalistas. Visto dessa forma "o campo passa a ser entendido como espaço pedagógico, espaço educador, formador de sujeitos e não mais como lugar da alienação, do atraso, habitação e espaço de pessoas incultas" (SOUZA, 2013, p. 18-19). No entanto há aqueles, que se constituem como maioria, que veem a floresta, suas árvores, animais e sua gente apenas como a potencial possibilidade de exploração e acúmulo de riquezas.

Ao falar sobre a diversidade do povo brasileiro em uma análise comparativa, a partir das Diretrizes Operacionais para a Educação do Campo, Silva (2002), é enfática ao defender um currículo que seja coerente com a vida das pessoas:

Somos plural! E assim precisam ser a nossas escolas. Escolas com propostas curriculares próprias, com projetos político-pedagógicos articulados e coerentes com os projetos de vida dos povos; onde os trabalhadores do campo [...] sejam protagonistas e não meros destinatários. Para que tal 


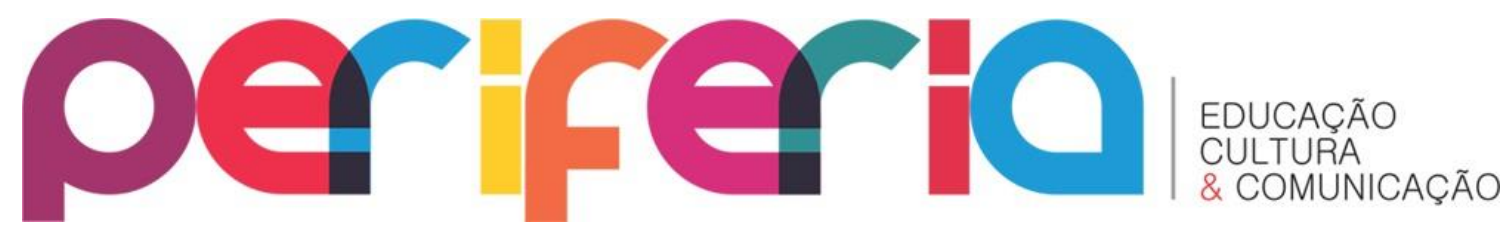

reivindicação se torne realidade, é importante construir políticas públicas que respeitem e contemplem a alteridade constitutiva do Brasil (p. 116).

A edificação dessa escola, de fato democrática e plural só se constituirá a partir do momento em que houver esforço coletivo, de sujeitos organizados do campo e de ações governamentais.

Pensando em compreender melhor as ações do educador do campo/floresta e sua polivalência é que desenvolveremos o item a seguir.

\section{A Polivalência do trabalho docente no Campo/Floresta}

O trabalho docente em escolas monodocentes no campo perpassam conhecimentos e competências que vão além do trabalho do professor. Além do trabalho de ensinar o professor deve, nesse contexto, trabalhar na gestão de contextos educativos, na gestão das aprendizagens de todas as áreas do conhecimento que perpassam o currículo escolar, na gestão comunitária, na organização do espaço escolar e na representação imagética da escola enquanto instituição estatal. Em síntese, é no contexto da escola do campo que o labor docente se faz intensificado por meio:

1. Da profissionalidade polivalente;

2. Da atuação profissional do professor como representação imagética da instituição escola;

3. Da gestão da comunidade - o professor representa o saber da comunidade;

4. Da gestão do seu processo de aceitação pela comunidade;

5. Do desempenho da atividade de gestão escolar, de secretário escolar, de serviços gerais, de merendeiro - as múltiplas funções que exigem policompetências;

6. Da Gestão do "local da comunidade" no currículo vivo do seu ensinar como professor rural;

7. Dos desafios do trabalho monodocente em salas multisseriadas;

8. Da necessidade constante de trabalhar com a criatividade e desenvoltura em resposta às precárias condições materiais da escola e do lugar;

9. Do desafio de insucesso escolar provocado pelas precárias condições materiais e pela difícil atuação em contextos multisseriados;

10. Do trabalho pedagógico com os alunos (as) em excesso e mistura do trabalho pedagógico com o administrativo da escola;

11. Da busca de uma educação que atenda às condições de vida da comunidade e as necessidades ambientais;

12. Da busca pela tolerância com os ritmos de aprendizagem à frustação, e uma atitude flexível para vicissitudes inerentes ao trabalho rural;

13. Da tensão entre a permanência e a repulsa da população e a constante ameaça da migração; 


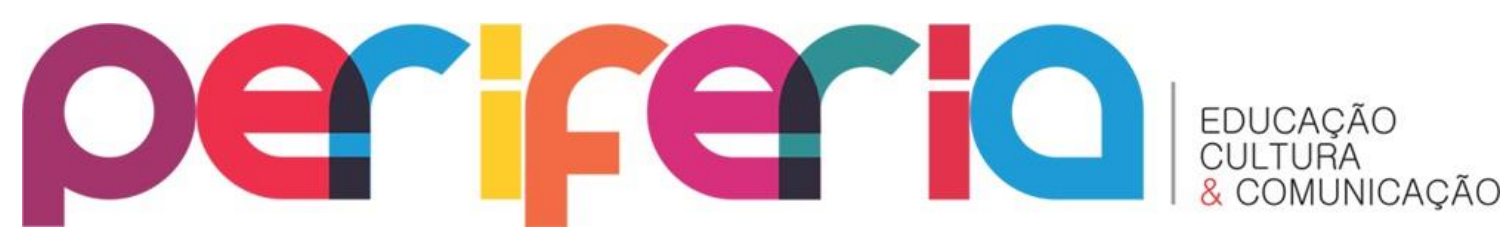

14. Do trabalho com crianças com características específicas: as de população rural.

Nos documentos oficiais do Ministério da Educação observa-se a consciência deste problema, que consideramos ainda pouco debatida entre os pesquisadores, principalmente no tocante a intensificação e precarização do trabalho docente nestes espaços. Para o MEC (2006):

\begin{abstract}
Quanto à atuação do professor, especialmente nas classes multisseriadas, verifica-se que: (1) há um acúmulo de tarefas para o professor que, além de ser docente, é muitas vezes também gestor escolar, secretário e funcionário administrativo, (2) existe um grande isolamento do trabalho docente, na medida em que o professor trabalha sozinho, praticamente sem contato com outros professores, orientadores e supervisores. Apenas essas duas constatações geram a necessidade de estabelecimento de políticas públicas que visem, de um lado, à organização de núcleos de ações administrativas que liberem o professor para desenvolver integralmente sua atividade principal: a docência, e, de outro, à implantação de núcleos pedagógicos que quebrem o isolamento do professor das escolas unidocentes, fazendo com que professores de uma mesma região possam trocar experiências, num processo de educação permanente. Importante destacar que todas as questões aqui apresentadas, tanto as de formação como as de atuação do professor nas Escolas do Campo, exigem do poder público ações concretas de valorização profissional, inclusive com o reconhecimento das funções que o professor exerce e que não são reconhecidas pela carreira, e o estabelecimento de planos de cargos e salários compatíveis com a alta prioridade da Educação do Campo, no contexto do desenvolvimento global da sociedade brasileira ( $\mathrm{p}$. 66-67).
\end{abstract}

Queremos enfatizar aqui apenas alguns dos aspectos do trabalho docente em escolas monodocentes que exigem do professor, pelo menos, quatorze competências diferentes para realização do seu trabalho diário. Como descreveremos algumas a seguir:

a) No trabalho educativo no campo introdução de tarefas polivalentes para o professor criam dificuldades para sua atuação. Ora este professor deve ser aquele capaz de assegurar os domínios de todas as áreas do conhecimento (Português, Matemática, História, Geografia, Ciências, Artes, Religião) que fazem parte da Base Curricular Nacional e, além disso, assegurar minimamente o domínio das letras e das operações matemáticas. É evidente que por si só o trabalho específico com a alfabetização parece ser caracterizador do trabalho do docente neste modelo de ensino. Porém, é preciso 


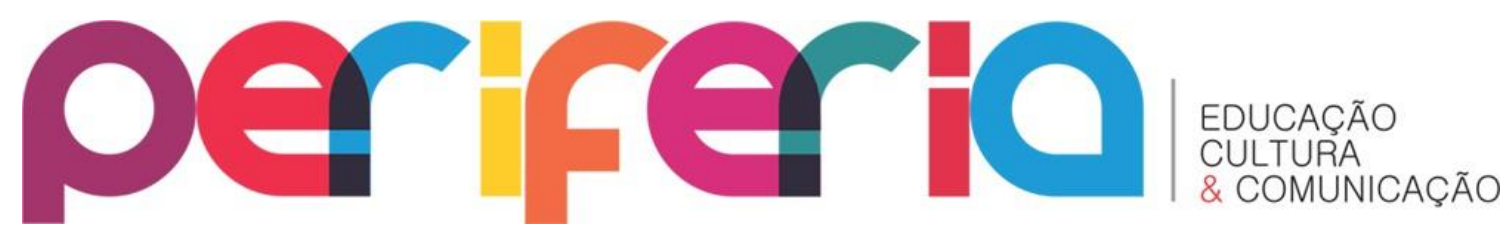

levar em conta um aspecto que intensifica demasiadamente o trabalho do professor no campo: o trabalho realizado em contexto de multiséries.

b) Ao trabalho docente para dá conta destes aspectos precisa tornar-se diversificado e fragmentado. A diversificação do trabalho, como dimensão da intensificação, é a diminuição dos tempos mortos de tal forma que o trabalho se torne cada vez mais denso (MARX, 2014, p.468). Em outras palavras, o professor deve realizar quatro ou cinco planejamentos para cada aula para atender a todos os alunos de sua sala. Esse processo de planejamento, diminui o tempo de descanso do professor levando-o a exaustão de sua capacidade criadora. É o ócio que permite o desenvolvimento da capacidade criativa (MASSI, 2000). Sem tempo para reflexão sobre o seu trabalho ou formas de aprimorá-lo o trabalho do professor torna-se estranhado e alienado (MARX, 2014).

c) Este processo levará a fragmentação, pois, na hora da execução do trabalho, o professor deverá administrar o curto espaço de tempo (4 horas aulas) para ensinar para quatro públicos diferentes no mesmo espaço. Qual trabalho docente é possível? Como se realiza essa distribuição entre as variáveis de trabalho real e tempo livre dos alunos na sala de aula? As múltiplas competências que este professor deve desenvolver nestes tempos livres para uns, mas de trabalho para os outros da sala permitem o transbordamento de seu trabalho. De tal forma, que o professor já não possui o domínio sobre o trabalho que executa pois não lhe são permitidos os ritmos que seu trabalho necessita para a transposição didática, a aplicação e a verificação da aprendizagem. Em síntese essas múltiplas atividades,

(...) representam aumento da intensidade do trabalho, sua superposição sobre as mesmas pessoas, bem como a introdução de práticas polivalentes que representam o acúmulo de tarefas, seja sob o ponto de vista quantitativo, seja sob o ponto de vista qualitativo, e de práticas versáteis e flexíveis implicam maior adensamento do trabalho real, sim, representam formas de intensificação (DAL ROSSO, 2008, p.155).

d) A intensificação do trabalho docente, nesse caso, pode condicionar o educador a mecanizar/automatizar suas práticas, alienando-a a mero ato de ensinar como ação despreocupado do fazer, exigência mercadológica de um sistema desprovido 


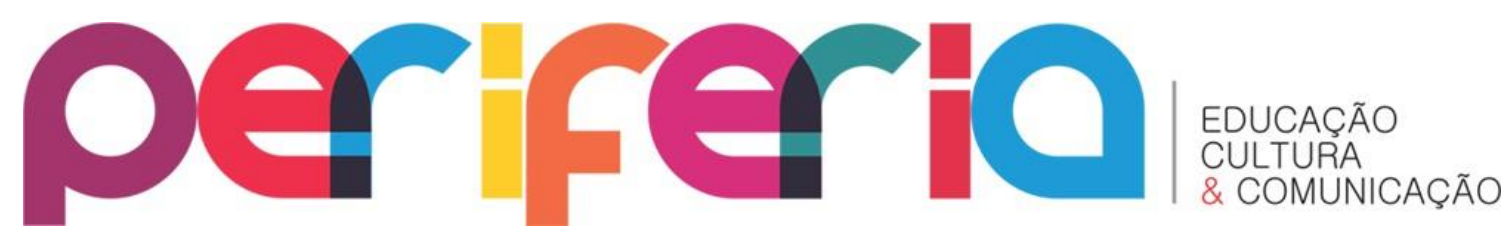

de sentimentos, que nas palavras de Candau (2000) produz em nosso "continente altos índices de analfabetismo, evasão, repetência e desigualdades de oportunidades educacionais" (p. 11).

e) Além destas competências o professor ainda tem que lidar com a gestão de sua aceitação pela comunidade. Competências de ordem biopsíquica devem se mobilizadas por este professor para construir junto a comunidade um processo de aceitação.

Em O si-mesmo como um outro, Paul Ricoeur nos alerta que a construção de uma identidade requer uma identificação com o outro, reconhecer - se no, com e na. Ora o professor além de construir sua identidade como professor do campo, deve, também, construir uma identidade com comunidade. Ao passo que, também, deve adquirir respeito, valor, e prestígio dentro da comunidade.

Se esta identidade não é construída e/ou conseguida gera mal-estar e sofrimento docente, uma vez que este deverá administrar os conflitos advindos de seu afastamento do habitus da comunidade (BOURDIEU, 2003).

Em suma, esse mal-estar se apresentará como o conjunto de reações e implicações biopsíquica que evidenciam este processo desajustado à profissão, capaz de gerar desconforto, constrangimento, stress, desmoralização, desencanto, desmotivação devido as vicissitudes do processo de construção identitária do professor na comunidade. Em síntese, adoecimento deste profissional no exercício de seu trabalho (ESTEVE, 1999).

f) A atividade polivalente deste professor não se dá apenas no exercício de sua profissão. Para além da ensinagem este professor exerce funções pelas quais ele não é remunerado. É ele o gestor escolar, o secretário escolar, os serviços gerais e o merendeiro da escola. Na fala da professora, entrevistada em uma comunidade do alto Juruá, percebemos estas multifuncionalidades:

Aqui eu faço tudo. De manhã cozinho junto com meu almoço logo a merenda. Só são 20 alunos, aí a tarde dou minhas aulas. A sala tem alunos de alfabetização, do segundo ano, terceiro e do quarto ano. Na hora do intervalo eu mesmo sirvo, esquento aí sirvo. Lavo tudo no final, quando vou lavar minhas coisas aí já lavo o da escola. Tem que ser assim! Eu também levo, quando vou para Cruzeiro do Sul as notas e tudo para a coordenação. Eles 


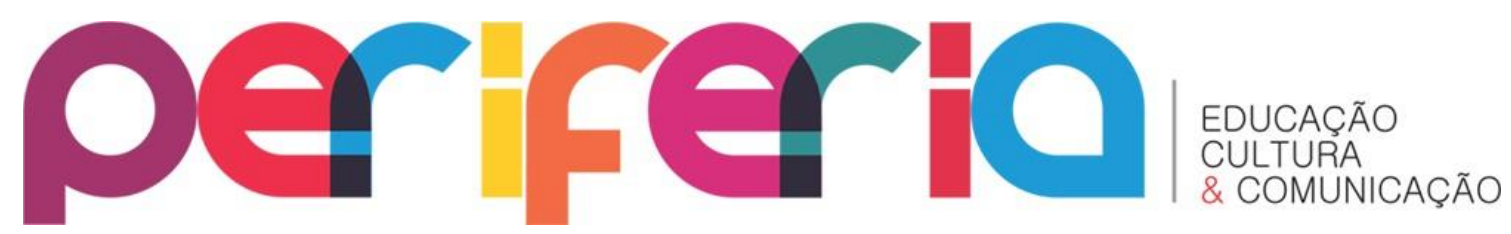

dificilmente aparecem, o diretor mesmo, aquele que ganha como diretor, visita a escola para fazer vistorias acerca do que a escola precisa em questões estruturais, ele vem uma vez ou outra. O coordenador a visita dele é semestral, vem para observar o plano e vê se a aula está acontecendo. (Relato de prática da disciplina Fundamentos e ensino multiseriado, realizado numa escola às margens do rio Juruá, 2016).

$\mathrm{Na}$ fala da professora fica evidente o processo constante de precarização das formas de trabalho revestido de novas formas de exploração. Marx analisando este processo apontava que o objetivo da produção capitalista é apenas reduzir o tempo de trabalho requerido para produzir determinada quantidade de mercadoria por isso sua jornada pode ser simultaneamente prolongada (MARX, 2014, p. 371). Destarte, como explica o próprio autor,

(...) o desenvolvimento da produtividade do trabalho na produção capitalista tem por objetivo reduzir a parte do dia de trabalho durante o qual o trabalhador tem de trabalhar para si mesmo, justamente para ampliar a outra parte durante a qual pode trabalhar gratuitamente para o capitalista (MARX, 2014, p. 372).

O mundo da vida do professor coloniza-se pelo mundo da escola e por seus processos, que no campo e na floresta resultam em um "maior dispêndio das capacidades físicas, cognitivas e emotivas do trabalhador com o objetivo de elevar quantitativamente os resultados" (DALL ROSSO, 2008, p. 23).

g) Esse maior dispêndio das capacidades físicas, cognitivas e emotivas do trabalhador com o objetivo de elevar quantitativamente ou qualitativamente os resultados do seu trabalho (DALL ROSSO, 2008). Força o professor a precisar desenvolver a criatividade constantemente para compensar as condições precárias com as quais trabalha. É ilustrativo a situação observada em uma escola do Campo no Vale do Juruá:

$\mathrm{Na}$ hora da correção das atividades, a professora convida os alunos a sentarem no chão, pois a escola contava com um quadro branco, porém, não possuía pincel para que fosse utilizado. As escritas necessárias eram feitas no chão de madeira da sala com o uso do giz branco e um pano úmido para apagar quando necessário o que haviam escrito (Relato de prática da disciplina Fundamentos do Ensino Multisseriado, 2016). 


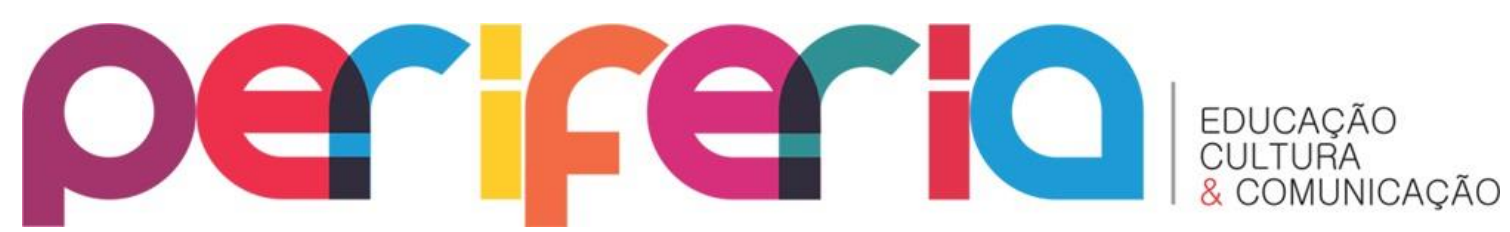

Estas formas de intensificação e precarização apenas escondem e escamoteiam os verdadeiros interesses da classe política quando se trata de educação. Trabalhar em ambiente precário é, sobretudo, denunciar que para o campo não há interesse de ensino socialmente qualificado que seja capaz de romper o status quo. Mas, usa-se a falta de condições materiais para se fomentar ainda mais a pobreza, a divisão social, o desemprego crônico e a violência social.

h) Nesse sentido o professor do campo é mais uma vítima de um sistema que o excluí, na medida em que não lhes são proporcionadas as devidas condições à superação da frágil formação, ou que não lhe é assegurada as condições materiais, salariais e pedagógicas para uma inserção mais crítica, reflexiva e com isso transformadora.

O INEP, em 2007, fez uma análise da escola do campo, tendo como base dados oficiais e informações oriundas dos movimentos sociais. Essas informações nos possibilitaram/possibilitam conhecer melhor a instituição escolar do campo e os sujeitos que atuam em seus espaços. O perfil do professor merece atenção e análise peculiar:

No caso específico da área rural, além da baixa qualificação e dos salários inferiores aos da zona urbana, eles enfrentam, entre outros problemas, sobrecarga de trabalho, alta rotatividade e dificuldades de acesso à escola, em função das condições das estradas e da falta de ajuda de custo para locomoção (p. 33).

Mesmo diante das imensas fragilidades e desafios a serem enfrentados o educador torna-se, frente à comunidade, a única referência do saber institucionalizado de um Estado que se mostra e se esconde através dos símbolos que ele (educador) representa, ora como gestor de conhecimentos, ora como representação imagética do currículo vivo de uma comunidade que não se faz presente nos contextos da sala de aula. Os motivos, além dos já mencionados, estão associados aos fortes condicionantes de uma educação que não se constitui para todos, além de uma visão historicamente estereotipada dos sujeitos do campo, que os coloca como incapazes, "desaculturados".

Essa visão destorcida, não é desprovida de intenções, é histórica e remonta aos idos do Brasil Colônia, onde existe apenas uma forma de ensinar e aprender, o jeito construído pelos letrados e detentores da "cultura" e sua didática catequética, consubstanciada no Ratio Studiorum. 


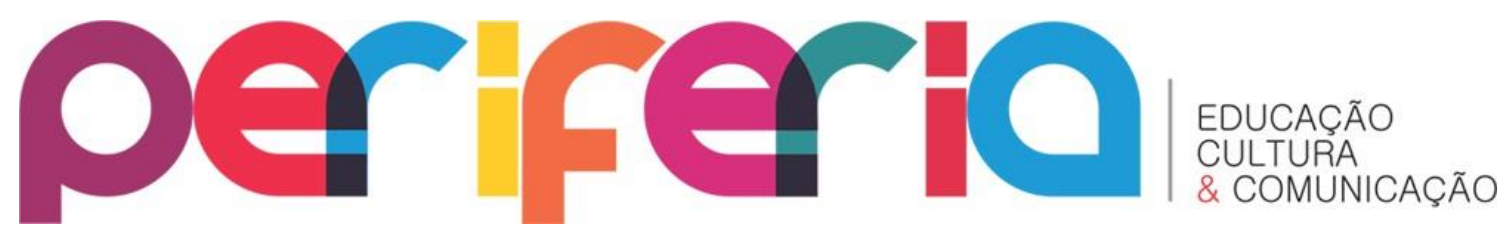

Como, então, pensar esses espaços educacionais do campo considerando sua realidade, seus saberes e contradições diante de tão grande fragilidade, especialmente na região do Alto Juruá, onde não se percebe um movimento orgânico caracterizado pela presença de trabalhadores e trabalhadoras rurais? Onde os processos formativos, no campo/floresta, parecem sofrer forte pressão desagregadora por parte do capitalismo mercante, acentuando ainda mais as disparidades campo/cidade.

A concepção apresentada por Freitas (2014), pode nos ajudar a melhor compreender essa distorção:

\footnotetext{
A educação na sociedade capitalista sofre as determinações da produção e da reprodução social. As condições de acesso à escolarização e aos níveis mais avançados de ensino são tão fortes ao ponto de considerar-se que a educação 'é o lugar por excelência da desigualdade, o domínio onde as riquezas são menos igualmente repartidas' (p. 77).
}

A superação dessas desigualdades e contradições só serão passiveis de serem equacionadas na medida em que os sujeitos e educadores do campo/floresta, mobilizados, construírem fissuras e espaços no encaminhamento de políticas públicas que os considerem, que os ouçam, que lhes garantam assento nos espaços de discussões e debates que os interessam.

\section{Considerações finais}

O trabalho é categoria ontológica do homem. Ao mesmo tempo que gera sofrimento e alienação, o hominiza e o humaniza. Pois, ao modificar a natureza, o ser se ver modificado pelo que criou ou se ver estranhado naquilo que criou. $\mathrm{O}$ homem "não transforma apenas o material sobre o qual opera; ele imprime ao material o projeto que tinha conscientemente em mira" (MARX, 2014, p. 212). Se o homem imprime ao material o projeto que conscientemente tem em mira, a ação docente como ato consciente de formar o humano é Trabalho.

Porém, em um ambiente onde este homem/mulher já não tem tempo de refletir sobre sua ação ou não tem condições para fazê-lo o trabalho também se torna alienado, alienante e precarizado, pois condiciona este indivíduo a agir sobre as vicissitudes do sua práxis. 


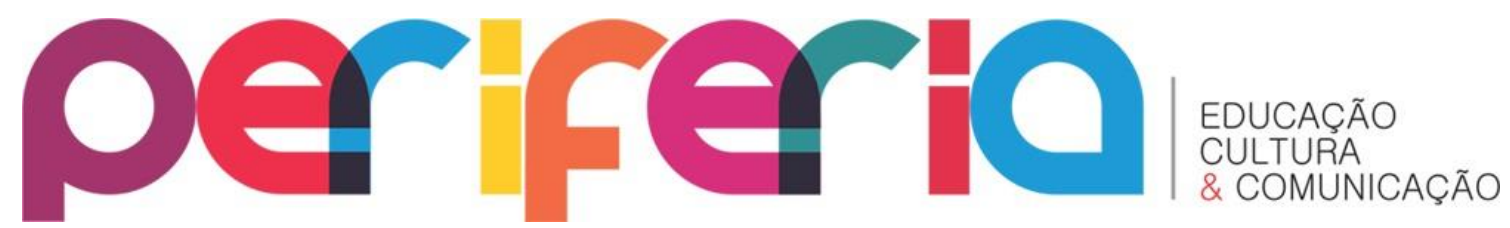

Essas condições adversas para trabalho com o ensino, leva os professores rotineiramente a enfrentam escassez físicas e materiais que entravam o seu desenvolvimento profissional e prejudicam gravemente a sua saúde física e mental: não há bibliotecas, na há livros, não há material básico (giz, pincéis), laboratórios, quadras de esportes, saneamento adequado (banheiro adequado), não há materiais necessários ao desenvolvimento do trabalho, há salas de aula deterioradas e falta de acompanhamento docente. Há um professor, um mestre escola, um professor que representa toda a imagem de escola que uma comunidade pode conceber.

Portanto, nas escolas do campo e da floresta na Amazônia é urgente definir um verdadeiro projeto profissional, considerando fatores pedagógicos, a formação inicial e contínua, salário, questões administrativas e de trabalho destinados a beneficiar todos os professores, com irrestrita defesa dos seus direitos, com a eliminação da intensificação e a precarização do trabalho. Este projeto envolveria, entre outras coisas, o aumento do salário, o pagamentos pelo trabalho feito além do seu, condições favoráveis para garantir o acesso à formação e respeito ao papel dos professores no processo educacional, a construção de uma escola que construísse oportunidades reais de emancipação e de superação da pobreza.

\section{Referências}

ALMEIDA JÚNIOR, A. M. de. O planejamento estratégico e a reforma educacional do Acre. 2006. 145f. (dissertação) de mestrado em educação - Universidade Federal do Rio de Janeiro - UFRJ. Rio de Janeiro, 2006. Disponível em: http://www.educacao.ufrj.br/ppge/dissertacoes/arnobioalmeidajunior.pdf. Acesso em: 28 jan. 2017.

ARROYO, M. G. Apresentação. In: SOUZA, Maria Antônia. Educação do campo: propostas e práticas pedagógicas do MST. Petrópolis, RJ: Vozes, 2006.

BOURDIEU, Pierre. A Dominação Masculina. Rio de Janeiro: Editora Bertrand Brasil, 2003.

BRASIL. CONGRESSO NACIONAL. Lei 9394, de 20/12/1996. Fixa as Diretrizes e Bases da Educação Nacional.

BRASIL/MEC. Conselho Escolar e a educação do campo. Elaboração Regina Vinhaes Gracindo... [et. al.]. Brasília : Ministério da Educação, Secretaria de Educação Básica, 2006.

CANDAU, Vera Maria (Org.). Reinventar a escola. 2a ed. Petrópolis-RJ: Vozes, 2000. DAL ROSSO. Sadi. Mais Trabalho! A intensificação do labor na sociedade contemporânea. São Paulo: Boitempo, 2008. 


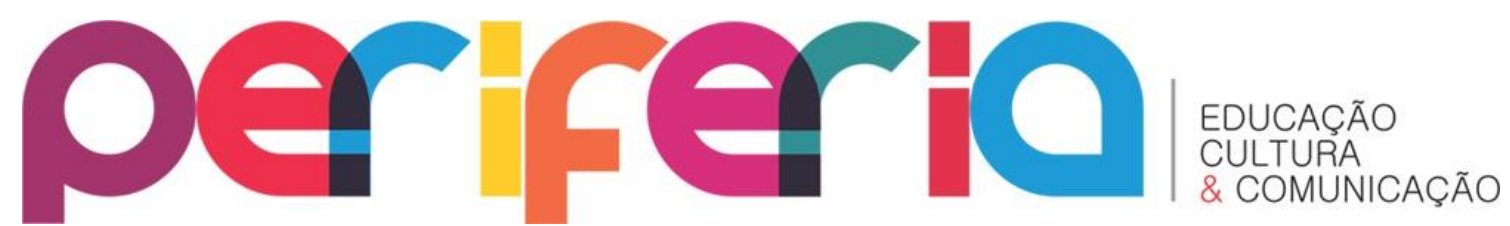

Dicionário infopédia da Língua Portuguesa com Acordo Ortográfico [em linha]. Porto: Porto Editora, 2003-2016. [consult. 2016-12-29 19:44:08]. Disponível em: https://www.infopedia.pt/dicionarios/lingua-portuguesa/monodocência. Acesso em: 23 jan. 2017.

ESTEVE, J. M. O mal-estar docente: a-sala-de-aula e a saúde dos professores tradução Durley de Carvalho Cavicchia - Bauru, SP, EDUSC, 1999.

FORMOSINHO, J. Educação para Todos - O Ensino Primário, de Ciclo único do ensino básico a ciclo intermédio da educação básica. Lisboa: Editorial do Ministério da Educação. 1998.

FREITAS, Marilene Corrêa da Silva. Pauperização e educação: expressão da questão social na análise de Louis Marmoz. In: ___ _ MARMOZ, L.; ARAUJO, W. P. Educação e pauperização: tradições, referências, aplicações. Manaus: Valer, 2014. p. 28-114.

MARX, K. O Capital: Crítica da economia política - Livro 1. Tradução de Reginaldo Sant ${ }^{\prime} A n n a . ~ 33^{a}$ ed. Rio de Janeiro: Civilização Brasileira. 2014.

MEC/INEP. Panorama da Educação do Campo. Brasília-DF, 2007.

MOLINA, Mônica Castagna (Org.). Educação do Campo e Pesquisa: questões para reflexão. - Brasília: Ministério do Desenvolvimento Agrário, 2006.

NETTO, J.P. Relendo a teoria marxista da história. In: SAVIANI, D.; LOMBARDI, J.C.; SANFELICE. J.L. (Org.). História e história da educação: o debate teóricometodológico atual. Campinas: Autores Associados; HISTEDBR, 1998.

OLIVEIRA, Raquel Alexandra de Brito Costa. Realidades da profissão do professor numa escola para todos. Edições do Autor, 2012. Disponível em http://www.dominiopublico.gov.br/download/texto/ea000686.pdf. Acesso em: $12 \mathrm{dez}$. 2016.

Programa de Pós-Graduação em Educação da Universidade Estadual do Amazonas. Manaus, 2013.

RICOEUR, Paul. O si-mesmo como um outro. Trad. Luci Moreira Cesar. Campinas: Papirus, 1991.

SILVA, Rosa Helena Dias da Silva. Diretrizes Operacionais para a Educação Básica nas Escolas do Campo: uma leitura comparativa, a partir da temática da educação escolar indígena. In: KOLLING, Edgar J.; CERIOLI, Paulo R \& CALDART, Roseli S (Orgs.). Educação do campo: identidade e políticas públicas. Brasília: Articulação Nacional por uma Educação do Campo, v. 4, 2002.

SOUZA, J. V. F. de. Educação do campo e da floresta: um olhar sobre a formação docente no programa Asas da Florestania no alto Juruá/Ac. 2013. 143f. (dissertação). Programa de Pós-Graduação em Educação da Universidade Federal do Amazonas UFAM. Manaus, 20113. 